\title{
CORROSION INHIBITION OF ALUMINIUM AND STEEL BY IMIDAZOLIUM SALTS
}

\author{
Šárka LANGOVÁ, Kristýna MARKOVÁ, Petr PÁNEK, Petra VÁŇOVÁ, Kateřina KONEČNÁ, \\ Šárka VICHERKOVÁ
}

\author{
VSB - Technical University of Ostrava, Ostrava, Czech Republic, EU, sarka.langova@vsb.cz \\ https://doi.org/10.37904/metal.2019.723
}

\begin{abstract}
The corrosion inhibition of aluminium and steel in the hydrochloric acid solution by 1-octyl-3-methylimidazolium bromide, 1-octyl-3-methylimidazolium hydrogensulphate and 1-dodecyl-3-methylimidazolium bromide was investigated using electrochemical and weight loss methods. The qualitative surface analysis was carried out. All the imidazolium salts under investigation act as mixed type inhibitors with predominantly cathodic action on aluminium and predominantly anodic action on steel. The inhibition efficiency of 1-octyl-3-methylimidazolium hydrogensulphate was higher than $99 \%$ for aluminium but decreased with time rapidly. The surface analysis elucidated the differences between the inhibition action on the mild and stainless steel. The Gibbs energy of adsorption was calculated by means of the Langmuir isotherm.
\end{abstract}

Keywords: Imidazolium salts; corrosion inhibition; polarization curve; steel; aluminium

\section{INTRODUCTION}

Aluminium and iron belong to the most often used construction materials. Although a compact, strongly adherent and continuous film is developed on aluminium upon exposure to the atmosphere, it can corrode in acid and bases [1-4]. Mild steel is also little resistant to corrosion. The utilization of organic inhibitors is a foremost corrosion prevention technique. Imidazolium-based salts are often used as corrosion inhibitors due to the presence of a $-\mathrm{C}=\mathrm{N}$ - group [5-7]. The inhibition efficiency depends on the strength of adsorption. The more negative the Gibbs energy absorption derived from thermodynamics of the adsorption process, the higher the inhibition potential. The experimental data often fit the Langmuir adsorption isotherm. Based on the good results with the alkylimidazolum salts, bromides were tested also as corrosion inhibitors for aluminium. In addition to bromides, 1-octyl-3-methylimidazolium hydrogensulphate was synthetized. The aim of this study was also to elucidate the differences in the inhibitor adsorption on the surface of the mild and stainless steel.

\section{EXPERIMENTAL}

\subsection{Materials}

The aluminium wire (99.9), the mild steel wire containing (wt. \%) $0.1 \mathrm{C}, 1.5 \mathrm{Mn}, 0.9 \mathrm{Si}, 0.03 \mathrm{~S}, 0.04 \mathrm{P}$ and balance $\mathrm{Fe}$ and the AISI 316 stainless steel wire of the composition (wt. \%) $0.07 \mathrm{C}, 1 \mathrm{Si}, 2 \mathrm{Mn}, 0.04 \mathrm{P}, 17 \mathrm{Cr}$, $10 \mathrm{Ni}$ and balance $\mathrm{Fe}$ were used. The steel specimens were abraded using various grades of emery papers, washed with distilled water, degreased in acetone and air-dried. The aluminium samples were not abraded in order to preserve the protective oxide layer. The solutions were prepared by dilution of inhibitors in hydrochloric acid of $1000 \mathrm{~mol} \mathrm{~m}^{-3}$ concentration. Imidazolium-based compounds were prepared in the microwave reactor using equimolar amounts of primary alkylbromide and 1-methylimidazole. 1-octyl-3-methylimidazolium bromide $(\mathrm{C} 8 \mathrm{MImBr})$ and 1-octyl-3-methylimidazolium hydrogensulphate $\left(\mathrm{C}^{2} \mathrm{MImHSO}_{4}\right)$ can be classified as ionic liquids. 1-dodecyl-3-methylimidazolium bromide $(\mathrm{C} 12 \mathrm{MImBr})$ has similar properties but it is solid at $20^{\circ} \mathrm{C}$.

\subsection{Electrochemical measurements}

All electrochemical measurements were carried out on Voltalab VM 40, Radiometer Analytical (France). A three-electrode electrochemical system was used with the steel wire as working electrode $\left(0.4 \mathrm{~cm}^{2}\right)$, platinum 
wire as counter electrode and $\mathrm{Ag} / \mathrm{AgCl}$ in $3 \mathrm{M} \mathrm{KCl}$ in the acid solution and SCE in the basic or neutral solution as reference electrode. All experiments were performed under atmospheric condition without stirring at $20^{\circ} \mathrm{C}$. Prior to the electrochemical measurements, a stabilization period of $45 \mathrm{~min}$ was allowed, which was proved to be sufficient to attain a quasi-equilibrium state for the open circuit potential (OCP) measurement. The potentiodynamic polarization curves were recorded in the potential range from -150 below to $+150 \mathrm{mV}$ above $\mathrm{OCP}$ at a scan rate of $1 \mathrm{mV} \cdot \mathrm{s}^{-1}$ in the positive direction. The EIS measurements were carried out in a frequency range from $100 \mathrm{kHz}$ to $100 \mathrm{mHz}$ with an amplitude of $5 \mathrm{mV}$ peak to-peak, using the AC signal at the OCP.

\subsection{Weight loss measurements and surface analysis}

Gravimetric measurements were performed with the samples prepared in the same way as the working electrode. The wires weighing about $0.2 \mathrm{~g}$ were immersed into the $1000 \mathrm{~mol} \mathrm{~m}^{-3} \mathrm{HCl}$ solution $(20 \mathrm{ml})$ with or without the inhibitor for several days and the weight loss was determined. The inhibition efficiency for the weight loss measurements was calculated from the equation (1), where $W L^{0}$ is the weight loss in 1000 mol $\mathrm{m}^{-3} \mathrm{HCl}$ solution and $W L^{i}$ is the weight loss in the presence of the inhibitor.

$I E_{W L}=\frac{W L^{0}-W L^{i}}{W L^{0}} \times 100$

The surface analysis was carried out using a scanning electron microscope QUANTA 450 FEG EDX, equipped with the EDX analyzer. The snaps were acquired in the secondary electrons mode.

\section{RESULTS AND DISCUSSION}

\subsection{Potentiodynamic polarization curves and electrochemical impedance spectroscopy}

The electrochemical parameters as corrosion potential $E_{c o r}(m V)$, corrosion current density icor $\left(\mathrm{mA} / \mathrm{cm}^{2}\right)$, cathodic and anodic Tafel slopes $\beta_{c}(\mathrm{mV})$ and $\beta_{a}(\mathrm{mV})$ and polarization resistance $R_{p}\left(\Omega \cdot \mathrm{cm}^{2}\right)$ were calculated via the analysis tool incorporated in VM 40 software (Table 1). The inhibition efficiency $I E_{i}(\%)$ was calculated from the following equation, where $\mathrm{i}^{0}$ and $\mathrm{i}^{\mathrm{i}}$ is the corrosion current density without and with the inhibitor:

$I E_{i}=\frac{i^{0}-i^{i}}{i^{0}} \times 100$

Figure 1 presents the polarization curves of mild steel in $1000 \mathrm{~mol} \mathrm{~m}{ }^{-3} \mathrm{HCl}$ containing 1-octyl-3methylimidazolium hydrogensulphate. It can be seen that the corrosion potential is shifted slightly to the positive direction depending on the inhibitor concentration. Because the difference is less than $85 \mathrm{mV}$, this compound can be classified as mixed type inhibitor with a predominant anodic action. The corrosion current densities in the presence of the inhibitor are lower than without this compound and the inhibition efficiency is only slightly dependent on the inhibitor concentration. It reaches $86 \%$ for the highest concentration. The inhibitive effect was tested also for aluminium (Figure 2). The difference between the corrosion current densities with and without inhibitor are much more significant. In that case the cathodic action can be seen. The inhibition efficiency is higher than $99 \%$ for all the concentrations.

For the EIS measurements, an equivalent circuit with the solution resistance $R_{S}$ in series with the parallel combination of the constant phase element (CPE) and the polarization resistance $R_{P}$ was used. The polarization resistance includes all the metal/solution interface resistances - the charge transfer resistance, accumulation resistance and diffusion layer resistance. The EIS measurements were evaluated by means of EIS analyser software. The inhibition efficiency was calculated from the equation (3), where $R_{p}$ and $R_{p}{ }^{0}$ are the polarization resistances of the solution with and without the inhibitor. The values were slightly lower than those obtained from the polarization measurements.

$I E_{E I S}=\frac{R_{P}-R_{P}^{0}}{R_{P}} x 100$ 


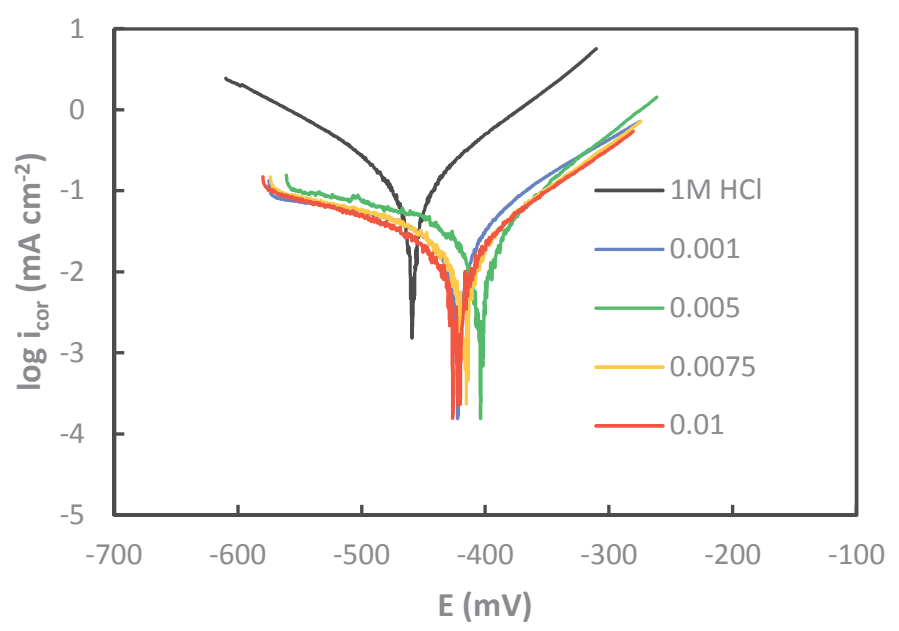

Figure 1 Potentiodynamic polarization curves of corrosion inhibition of mild steel in $1000 \mathrm{~mol} \mathrm{~m}^{-3} \mathrm{HCl}$ in the absence and presence of 1-octyl-3-methylimidazolium hydrogensulphate

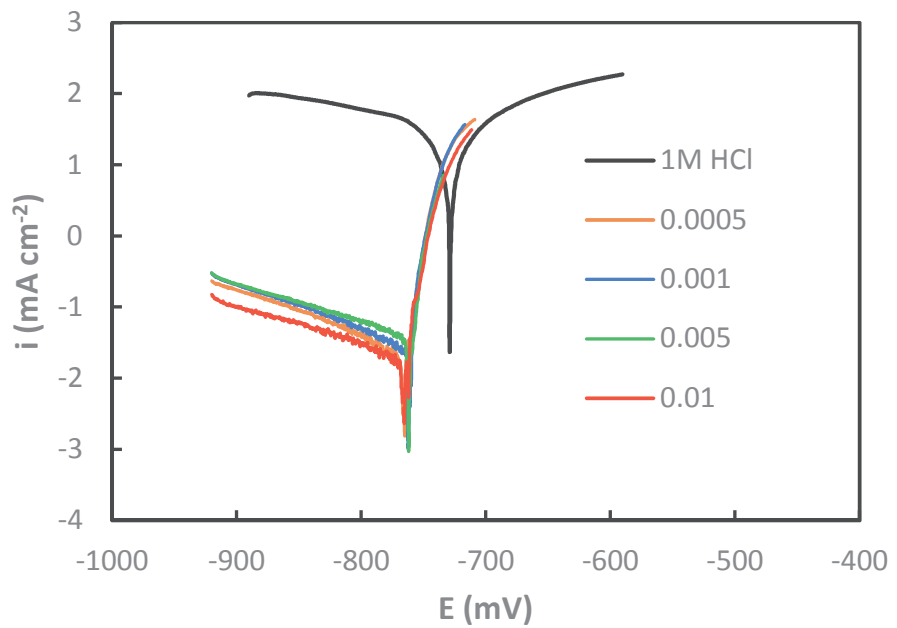

Figure 2 Potentiodynamic polarization curves of corrosion inhibition of aluminiumin $1000 \mathrm{~mol} \mathrm{~m}^{-3} \mathrm{HCl}$ in the absence and presence of 1-octyl-3-methylimidazolium hydrogensulphate

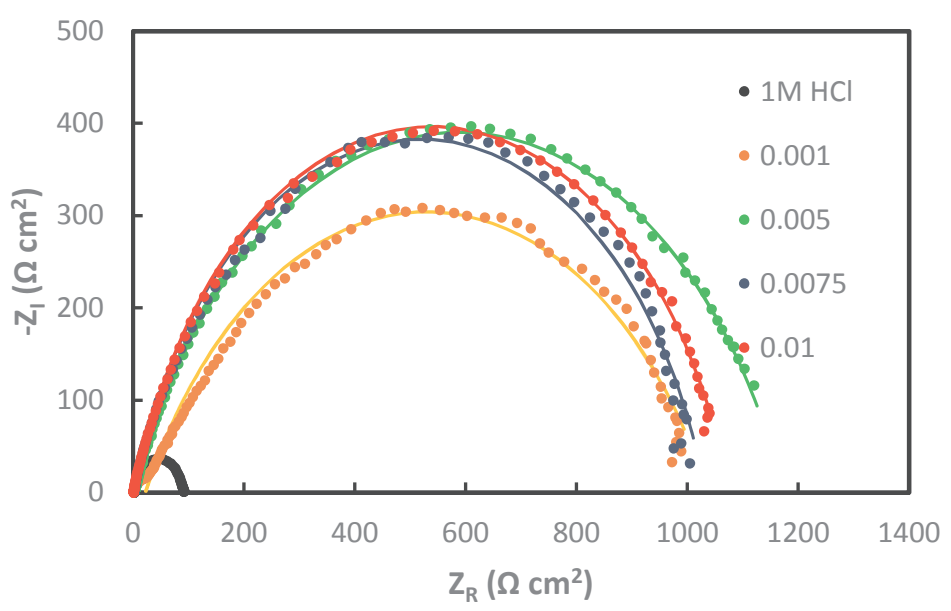

Figure 3 Nyquist plots of corrosion inhibition of mild steel in $1000 \mathrm{~mol} \mathrm{~m}^{-3} \mathrm{HCl}$ in the absence and presence of 1-octyl-3-methylimidazolium hydrogensulphate 


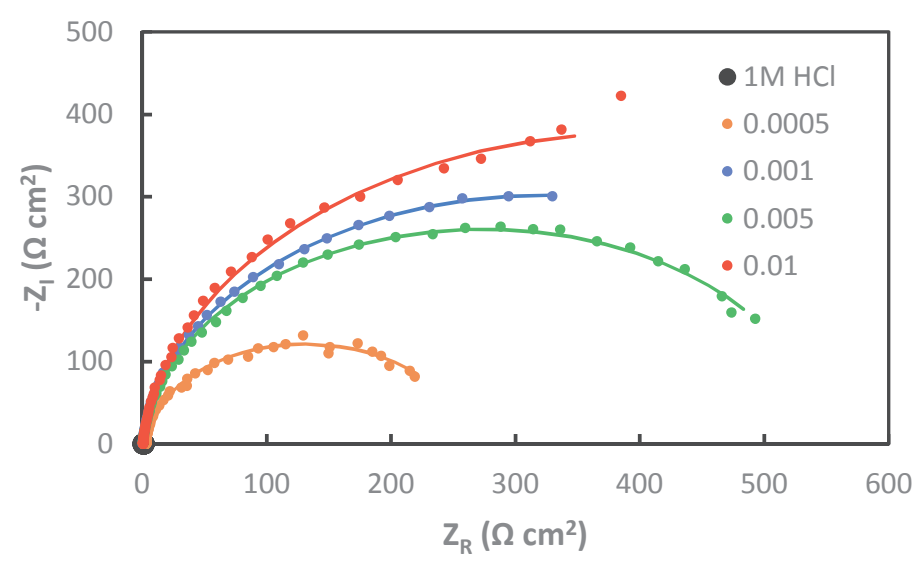

Figure 4 Nyquist plots of corrosion inhibition of aluminium in $1000 \mathrm{~mol} \mathrm{~m}^{-3} \mathrm{HCl}$ in the absence and presence of 1-octyl-3-methylimidazolium hydrogensulphate

Table 1 Electrochemical polarization parameters for mild and stainless steel in $1 \mathrm{M} \mathrm{HCl}$ solution in the absence and presence of 1-alkyl-3-methylimidazolium bromides at $20^{\circ} \mathrm{C}$.

\begin{tabular}{|c|c|c|c|c|c|c|}
\hline & $\mathbf{c}\left(\mathbf{m o l ~ d m}^{-3}\right)$ & $\beta_{a}(\mathbf{m V} / \mathbf{d e c})$ & $-\beta_{c}(\mathbf{m V} / \mathbf{d e c})$ & $E_{c o r}(\mathbf{m V})$ & $R_{\mathbf{p}}\left(\Omega \mathbf{~ c m}^{2}\right)$ & IE $(\%)$ \\
\hline \multirow{3}{*}{$\begin{array}{c}\text { Mild steel, } \\
\text { C8MImHSO4 }\end{array}$} & blank & 97 & 114 & -461 & 161 & \\
\cline { 2 - 7 } & 0.001 & 109 & 385 & -423 & 833 & 76 \\
\cline { 2 - 7 } & 0.01 & 94 & 204 & -417 & 714 & 86 \\
\hline \multirow{3}{*}{$\begin{array}{c}\text { Aluminium, } \\
\text { C8MImHSO4 }\end{array}$} & blank & 158 & 282 & -730 & 0.756 & \\
\cline { 2 - 7 } & 0.0005 & 10 & 130 & -767 & 189 & 99 \\
\hline Aluminium,C8MImBr & 0.005 & 10 & 198 & -763 & 101 & 99 \\
\hline AISI 316 & 0.001 & 6 & 133 & -762 & 909 & 99 \\
\hline AISI 316, C8MImBr & 0.001 & 20 & 208 & -249 & 313 & 39 \\
\hline AISI 316, C12MImBr & 0.001 & 22 & 189 & -245 & 370 & 68 \\
\hline
\end{tabular}

The use of CPE represents the more accurate fit in the case of deviation from an ideal capacitor as a result of different phenomena like surface roughness, inhibitor adsorption, porous layer formation, etc. The impedance $Z$ of $C P E(Q)$ is given by the equation (4).

$Z_{C P E}=\left[Q(j \omega)^{n}\right]^{-1}$

The exponent $\mathrm{n}$ used to be $0.7-1$ and is equal to one in case of the ideal capacitor. The solution resistances are not reported in the table because of the considerable calculation error. The values were less than $2 \Omega \mathrm{cm}^{2}$. Figures 3 and $\mathbf{4}$ show the Nyquist plots of the mild steel and aluminium in the absence and presence of C8MImHSO 4 . The lines present the fitted spectrum and the points indicate the experimental values.

\subsection{Surface analysis, weight loss measurements and adsorption isotherms}

The surface analysis indicated the preferential inhibitor adsorption on iron. On the other hand, the alloying elements, especially molybdenum, do not interact with inhibitor C8MImBr so much (Table 2). Figure 5 presents the surface analysis of the original mild steel, a wire after 7 days immersion in $\mathrm{HCl}$ solution and after 7 days immersion in $0.001 \mathrm{M} \mathrm{1-octyl-3-methylimidazolium} \mathrm{hydrogensulphate} \mathrm{solution.} \mathrm{The} \mathrm{protective} \mathrm{effect} \mathrm{of}$ the inhibitor can be seen. 
The weight loss measurements indicated that the inhibition efficiency for the mild steel remained after seven days immersion into the inhibitor solution while in the case of AISI 316 stainless steel id decreased strongly (Table 3). The aluminium wire was completely dissolved after seven days in the solution of all the inhibitors and the inhibition efficiency was zero.

Table 2 Semi-quantitative X-ray microanalysis of AISI 316 wires surface - the original samples (untreated), the samples immersed into the $1 \mathrm{M} \mathrm{HCl}$ solution, the samples immersed into the $1 \mathrm{M} \mathrm{HCl}$ solution with the inhibitor $\mathrm{C} 8 \mathrm{MImBr}$ or $\mathrm{C} 12 \mathrm{MImBr}$ after 7 days (wt \%).

\begin{tabular}{|c|c|c|c|c|c|c|c|}
\hline Name & $\mathrm{O}$ & $\mathrm{Si}$ & $\mathrm{Cr}$ & $\mathrm{Mn}$ & $\mathrm{Fe}$ & $\mathrm{Ni}$ & $\mathrm{Mo}$ \\
\hline Untreated & 2.51 & 0.62 & 16.97 & 1.66 & 65.38 & 10.36 & 2.49 \\
\hline $1 \mathrm{M} \mathrm{HCl}$ & 8.44 & 0.65 & 15.59 & 1.82 & 57.60 & 9.28 & 6.63 \\
\hline $0.001 \mathrm{M} \mathrm{C} 8 \mathrm{MImBr}$ & 4.58 & 0.58 & 16.72 & 1.58 & 63.02 & 9.91 & 3.60 \\
\hline $0.001 \mathrm{M} \mathrm{C12MImBr}$ & 7.36 & 0.67 & 16.31 & 1.57 & 58.97 & 9.33 & 5.79 \\
\hline
\end{tabular}

Table 3 Inhibition efficiency after 1 and 7 days calculated from the weight loss measurements

\begin{tabular}{|c|c|c|c|c|c|c|c|c|}
\hline & $\begin{array}{c}0.005 \\
\mathrm{C} 8,1\end{array}$ & $\begin{array}{c}0.005 \\
\mathrm{C} 8,7\end{array}$ & $\begin{array}{c}0.005 \\
\mathrm{C} 12,1\end{array}$ & $\begin{array}{c}0.005 \\
\mathrm{C} 12,7\end{array}$ & $\begin{array}{c}0.0075 \\
\mathrm{C} 8,1\end{array}$ & $\begin{array}{c}0.0075 \\
\mathrm{C} 8,7\end{array}$ & $\begin{array}{c}0.0075 \\
\mathrm{C} 12,1\end{array}$ & $\begin{array}{c}0.0075 \\
\mathrm{C} 12,7\end{array}$ \\
\hline Mild steel & 91.7 & 97.5 & 91.1 & 96.8 & & & & \\
\hline AISI 316 & 23.2 & 5.6 & 21.3 & 6.3 & 17.6 & 6.7 & 30.1 & 16.6 \\
\hline
\end{tabular}

Gibbs energy of adsorption represents the strength of adsorption or desorption between adsorbate and adsorbent. The values of surface coverage, $\Theta$ (IE / 100) for the different concentration of 1-alkyl-3methylimidazolium salts proved to fit Langmuir adsorption isotherm (5). $C$ is he molar concentration of the inhibitor and $K$ is the equilibrium constant of the adsorption reaction. Figure 6 presents curve fitting of the data obtained from polarization curves to Langmuir isotherm for mild steel in $1000 \mathrm{~mol} \mathrm{~m}^{-3} \mathrm{HCl}$ and 1-octyl-3methylimidazolium hydrogensulphate. The value of Gibbs energy was $-32.2 \mathrm{~kJ} / \mathrm{mol}$.

$\frac{c}{\theta}=c+\frac{1}{K}$
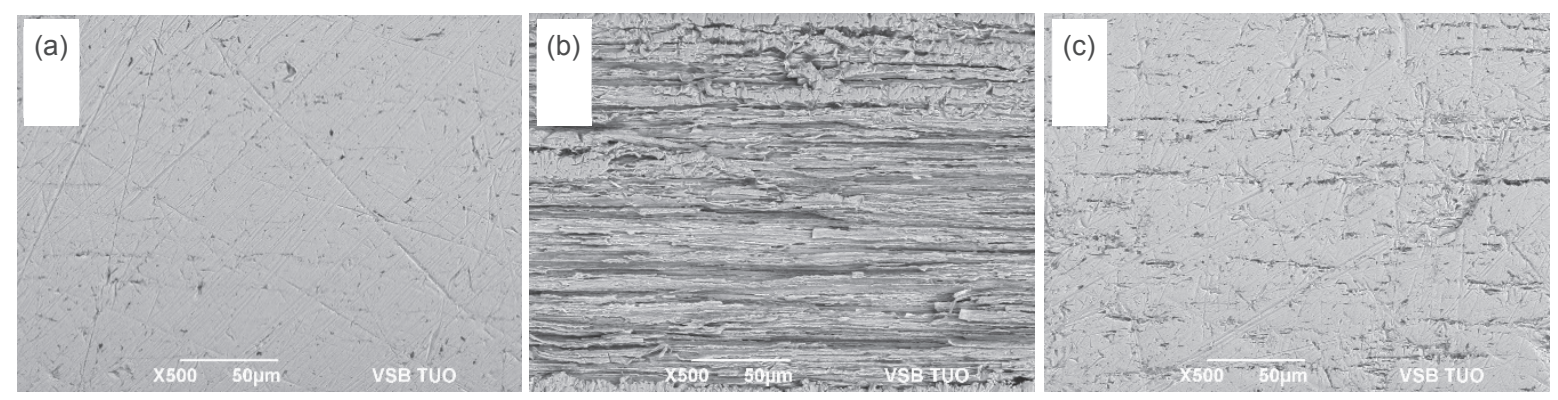

Figure 5 SEM analysis of the original mild steel (a), a wire after 7 days immersion in $1 \mathrm{M} \mathrm{HCl}$ solution (b)and after 7 days immersion in $0.001 \mathrm{M}$ 1-octyl-3-methylimidazolium hydrogensulphate solution (c)

\section{CONCLUSION}

1-octyl-3-methylimidazolium hydrogensulphate, 1-octyl-3-methylimidazolium bromide and 1-dodecyl-3methylimidazolium bromide proved to be mixed-type inhibitor with predominant cathodic inhibitive effect for aluminium. The inhibition efficiency was higher than $99 \%$ after 45 minutes but it decreased to zero after seven days. All the compounds under investigation have the predominant anodic inhibitive effect in the case of the mild and stainless steel. While the inhibition efficiency remained higher than $90 \%$ for the mild steel, this value 
was less than $50 \%$ and decreased more than twice after seven days for the stainless steel. The surface analysis demonstrated that 1-octyl-3-methylimidazolium bromide is probably adsorbed on iron in preference and the interaction with molybdenum is weaker. The value of the Gibbs energy obtained from the Langmuir isotherm for mild steel 1-octyl-3-methylimidazolium hydrogensulphate from the polarization curves was -32.2 $\mathrm{kJ} / \mathrm{mol}$.

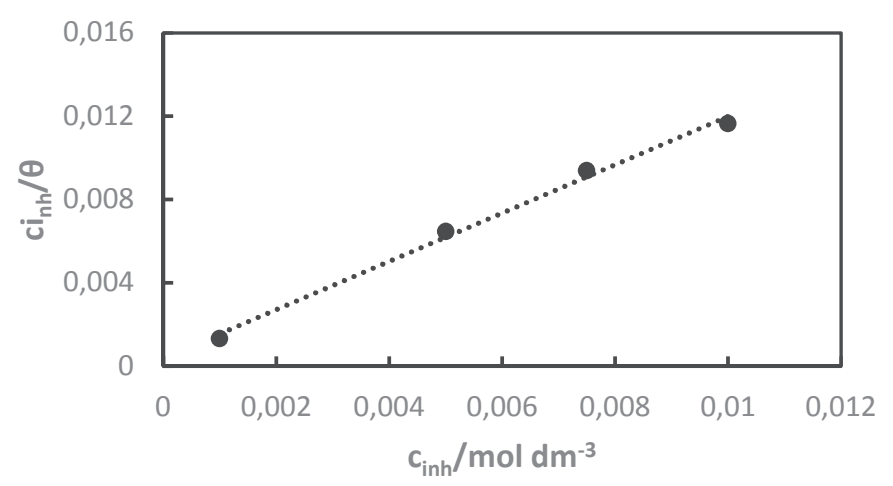

Figure 6 Curve fitting of the data obtained from polarization curves to Langmuir isotherm for mild steel in $1000 \mathrm{~mol} \mathrm{~m}^{-3} \mathrm{HCl}$ and 1-octyl-3-methylimidazolium hydrogensulphate

\section{ACKNOWLEDGEMENTS}

This work was financially supported by the Ministry of Education, Youth and Sports of the Czech Republic in the "National Feasibility Program I", project LO1208 "TEWEP" and by Ministry of Industry and Trade, project TRIO FV10089, and by the project of Specific research: SP 2018/79.

\section{REFERENCES}

[1] XHANARI, Klodian., MATJAŽ, Finšgar. Organic corrosion inhibitors for aluminum and its alloys in chloride and alkaline solutions: A review. Arabian Journal of Chemistry, in press

[2] QURAISHI, M. A., RAFIQUEE, M. Z. A, SADAF KHAN, NIDHI SAXENA. Corrosion inhibition of aluminium in acid solutions by some imidazoline derivatives. J Appl Electrochem. 2007. vol. 37, pp. 1153-1162. DOI 10.1007/s10800-007-9379-0.

[3] BOKATI, Kazem Sabet., DEHGHANIAN, Changiz. Adsorption Behavior of $1 \mathrm{H}$-benzotriazole Corrosion Inhibitor on Aluminum alloy 1050, Mild steel and Copper in Artificial Seawater. Journal of Environmental Chemical Engineering [online]. https://doi.org/10.1016/j.jece.2018.02.015.

[4] GRUBAČ, Z., R. BABIĆ, R. and METIKOŠ-HUKOVIĆ, M. Application of substituted N-arylpyrroles in the corrosion protection of aluminium in hydrochloric acid. Journal of Applied Electrochemistry. 2002. vol. 32, pp. 431438.

[5] VERMA, C., OLASUNKANMI, L. O., EBENSO, E. E., QUARISHI, M. A. Substituent effect on corrosion inhibition performance of organic compounds: A review. Journal of molecular liquids. 2018, vol. 251, pp. 100-118.

[6] YESUDASS, S, ADEKUNLE, A. S., OLASUNKANMI L. O., BAHADUR, I., BASKAR, R, KABANDA, M. M., OBOT, I. B., EBENSO, E. E. Experimental, quantum chemical and Monte Carlo simulation studies on the corrosion inhibition of some alkyl imidazolium ionic liquids containing tetrafluoroborate anion on mild steel in acidic medium. Journal of Molecular Liquids. 2015, vol. 211, pp. 105-118.

[7] ZHANG, Q. B., HUA, Y. X. Corrosion inhibition of mild steel by alkylimidazolium ionic liquids in hydrochloric acid. Electrochimica Acta. 2009, vol. 54, pp. 1881-1887. 